\title{
Developmental Requirement of gp130 Signaling in Neuronal Survival and Astrocyte Differentiation
}

\author{
Kinichi Nakashima, ${ }^{1,2}$ Stefan Wiese, ${ }^{3}$ Makoto Yanagisawa, ${ }^{1}$ Hirokazu Arakawa, ${ }^{1}$ Naoki Kimura, ${ }^{1}$ \\ Tatsuhiro Hisatsune,, ${ }^{4}$ Kanji Yoshida, ${ }^{5}$ Tadamitsu Kishimoto, ${ }^{6}$ Michael Sendtner, ${ }^{3}$ and Tetsuya Taga ${ }^{1}$ \\ ${ }^{1}$ Department of Molecular Cell Biology and ${ }^{2}$ Cell Fate Modulation Research Unit, Medical Research Institute, Tokyo \\ Medical and Dental University, Tokyo, 101-0062, Japan, ${ }^{3}$ Clinical Research Unit for Neuroregeneration, Department of \\ Neurology, University of Würzburg, Würzburg, 97080, Germany, ${ }^{4}$ Division of Integrated Biosciences, Graduate School for \\ Frontier Science, The University of Tokyo, Tokyo, 113-8657, Japan, and 5Department of Molecular Immunology, \\ Research Institute for Microbial Diseases, ${ }^{6}$ Osaka University, Osaka, 565-0871, Japan
}

gp130 is a signal-transducing receptor component used in common by the interleukin-6 (IL-6) family of hematopoietic and neurotrophic cytokines, including IL-6, IL-11, leukemiainhibitory factor, ciliary neurotrophic factor, oncostatin-M, and cardiotrophin-1. We have examined in this study a role of gp130 in the nervous system by analyzing developmental cell death of several neuronal populations and the differentiation of astrocytes in gp130-deficient mice. A significant reduction was observed in the number of sensory neurons in L5 dorsal root ganglia and motoneurons in the facial nucleus, the nucleus ambiguus, and the lumbar spinal cord in gp130 -/- mice on embryonic day 18.5. On the other hand, no significant neuronal

The interleukin-6 (IL-6) family of cytokines, i.e., IL-6, IL-11, leukemia inhibitory factor (LIF), ciliary neurotrophic factor (CNTF), oncostatin-M (OSM), and cardiotrophin-1 (CT-1), display an array of biological functions (Taga et al., 1989; Kishimoto et al., 1994; Taga and Kishimoto, 1997). All these cytokines use gp130 in their respective receptor complexes as a signaltransducing component (Taga et al., 1989, 1992; Kishimoto et al., 1994; Stahl and Yancopoulos, 1994; Taga and Kishimoto, 1997), which explains their functional overlaps. These cytokines signal through either homodimers of gp130 (for IL-6 and IL-11) or heterodimers comprising gp130 and a dimer partner, such as an LIF receptor (LIFR) (for LIF, CNTF, OSM, and CT-1) and an OSM-specific receptor component (OSMR) (for OSM) (Davis et al., 1993; Murakami et al., 1993; Kishimoto et al., 1994; Taga and Kishimoto, 1997).

Mice lacking IL-6, LIF, or CNTF displayed phenotypes less severe than expected from pleiotropic nature of each cytokine, presumably because of compensation by the remaining gp130-

\footnotetext{
Received Jan. 13, 1999; revised April 14, 1999; accepted April 20, 1999.

This work has been supported by a grant-in-aid from the Ministry of Education, Science, and Culture, Human Frontier Science Program, Cell Science Research Foundation, Kowa Life Science foundation, and Cell Fate Modulation Research Unit of Medical Research Institute of Tokyo Medical and Dental University. We thank Dr. Hiroshi Kiyama for helpful comments and discussions and Dr. Kiyoshi Yasukawa for generously providing us with sIL-6R. We are very grateful to Yuko Nakamura for her excellent secretarial assistance. We also thank Kyoko Saito for technical help. Preparation of histological samples was done with generous help and suggestions of Tayoko Tajima, Hiromi Tanizawa, Dr. Toshihiro Kuroiwa, and Dr. Riki Okeda.

Correspondence should be addressed to Dr. Tetsuya Taga, Department of Molecular Cell Biology, Medical Research Institute, Tokyo Medical and Dental University, 2-3-10 Kanda-Surugadai, Chiyoda-ku Tokyo 101-0062, Japan.

Copyright (C) 1999 Society for Neuroscience $\quad 0270-6474 / 99 / 195429-06 \$ 05.00 / 0$
}

loss was detectable on day 14.5, suggesting a physiological role of gp130 in supporting newly generated neurons during the late phase of development when naturally occurring cell death takes place. Moreover, expression of an astrocyte marker, GFAP, was severely reduced in the brain of gp130 -/- mice. Our data demonstrate that gp130 expression is essential for survival of subgroups of differentiated motor and sensory neurons and for the differentiation of major populations of astrocytes in vivo.

Key words: gp130; deficient mice; cytokine; astrocyte; motor neuron; sensory neuron stimulating cytokines (Stewart et al., 1992; Escary et al., 1993; Masu et al., 1993; Kopf et al., 1994). In contrast, mice lacking gp130 or LIFR die during development or shortly after birth (Li et al., 1995; Ware et al., 1995; Yoshida et al., 1996, 1998; Kawasaki et al., 1997). gp130-deficient mice exhibit defects in myocardium and hematopoiesis (Yoshida et al., 1996, 1998). Mice deficient for gp130 or LIFR show placental defects and reduced bone mass (Ware et al., 1995; Kawasaki et al., 1997; Yoshida et al., 1998).

Within the nervous system, LIF, CNTF, CT-1, and OSM support survival of several types of neurons in vitro (Ernsberger et al., 1989; Martinou et al., 1992; Taga, 1996; Horton et al., 1998). They induce cholinergic properties in cultured autonomic neurons (Yamamori et al., 1989; Patterson, 1994). CNTF induces differentiation of autonomic neurons (Ernsberger et al., 1989). IL-6 and IL-11 promote neuronal differentiation of pheochromocytoma and hippocampal precursors, respectively (Satoh et al., 1988; Mehler et al., 1993). Stimulation of gp130 also induces differentiation of astrocytes (Johe et al., 1996; Bonni et al., 1997; McKay, 1997). Mice deficient for either CNTF or LIF were born normally (Stewart et al., 1992; Escary et al., 1993; Masu et al., 1993), showing no developmental abnormalities in the nervous system, but exhibited mild loss of motor neurons in the adulthood (Masu et al., 1993). Crossing these two lines accelerated motor neuron degeneration, but the defect was still moderate (Sendtner et al., 1996). In contrast, CNTF receptor (CNTFR) knock-outs showed neonatal lethality and significant reduction in the number of motor neurons (DeChiara et al., 1995). A similar neurological defect was observed in LIFR-deficient mice (Li et al., 1995), suggesting the presence of a cytokine, other than CNTF, which 
binds to CNTFR and signals through an LIFR-gp130 complex. LIFR-deficient mice exhibited astrocyte loss as well (Ware et al., 1995; Koblar et al., 1998). Although mitotic oligodendrocytes were moderately reduced in the postnatal optic nerve of CNTFdeficient mice, astrocytes looked normal (Barres et al., 1996). It is thus of much interest to analyze neurological defects in gp130 knock-out mice in which all the signals from gp130/gp130, gp130/ LIFR, and gp130/OSMR dimers are lost. The present study has been done for this purpose.

\section{MATERIALS AND METHODS}

Animals. The effect of gp130 deficiency on the nervous system has not been extensively examined, partly because the gp130 knock-out mice on which we reported previously were on the genetic background of the mixture of 129 and C57BL/6 and died during development (Yoshida et al., 1996, 1998). In the present study, gp130 knock-out mice on the genetic background of ICR were used. On this genetic background, some gp130 null mice survive through the late stages of development to term at an incidence of $9 \%$ in total live newborns from gp130 +/- intercrossings (Kawasaki et al., 1997). Even in this case, the live newborns die shortly after birth, as observed previously with LIFR- and CNTFRdeficient mice. Mice were treated according to the guidelines of the Tokyo Medical and Dental University Animal Committee.

Cell culture. Neuroepithelial cells were prepared and cultured as described previously (Johe et al., 1996). In brief, telencephalons from embryonic day 14.5 (E14.5) mice were triturated in HBSS by mild and frequent pipetting with $1 \mathrm{ml}$ pipet tip (Gilson, Middleton, WI). Dissociated cells were cultured for $4 \mathrm{~d}$ in N2-supplemented DMEM-F-12 medium containing $10 \mathrm{ng} / \mathrm{ml}$ basic FGF (bFGF) ( $\mathrm{R}$ \& D Systems, Minneapolis, MN) (N2-DMEM-F-12-bFGF) on a $10 \mathrm{~cm}$ dish that had been precoated with poly-L-ornithine (Sigma, St. Louis, MO) and fibronectin (Life Technologies, Gaithersburg, MD). Telecephalon-derived cells were plated in one dish with $6 \mathrm{ml}$ of medium. Cells were then detached in HBSS and replated on chamber slides (Nunc, Naperville, IL) precoated as above at a density of $8 \times 10^{4}$ cells per well $(0.3 \mathrm{ml}$ each, cultured for $3 \mathrm{~d}$ ). N2-DMEM-F-12-bFGF medium supplemented with various cytokines were used for the cell culture.

Immunoblotting. Cells stimulated with either a combination of IL-6 $(100 \mathrm{ng} / \mathrm{ml})$ and soluble IL-6 receptor (sIL-6R) $(200 \mathrm{ng} / \mathrm{ml})$ or LIF (100 $\mathrm{ng} / \mathrm{ml}$; Genzyme, Boston, MA) were solubilized with NP-40 lysis buffer $[0.5 \%$ NP-40, 10 mm Tris-Cl, pH 7.4, $150 \mathrm{~mm} \mathrm{NaCl,} 3$ mм pAPMSF (Wako Chemicals, Osaka, Japan), $5 \mathrm{mg} / \mathrm{ml}$ aprotinine (Sigma), $2 \mathrm{~mm}$ sodium orthovanadate (Wako Chemicals), and $5 \mathrm{~mm}$ EDTA]. Lysates were immunoprecipitated with anti-gp130 antibody (Santa Cruz Biotechnology, Santa Cruz, CA) or anti-signal transducer and activator of transcription (STAT) 3 antibody (kindly provided by Dr. S. Akira, Research Institute for Microbial Disease, Osaka University, Suita, Japan). Precipitates and, in some cases, cell lysates were subjected to SDS-PAGE and subsequent immunoblotting with antibodies to phosphotyrosine (4G10; Upstate Biotechnology, Lake Placid, NY), LIFR (Santa Cruz Biotechnology), or STAT3 (Transduction Laboratories, Lexington, KY). Detection was done with an ECL system (Amersham, Arlington Heights, IL).

Histology. Mouse embryos were fixed with $4 \%$ paraformaldehyde in PBS and embedded in paraffin according to conventional procedures. Serial paraffin sections $(7 \mu \mathrm{m})$ prepared with an automated Leica (Nussloch, Germany) rotation microtome were mounted on glass slides and subjected to Nissl staining. Neurons within the facial nucleus, the nucleus ambiguus, lumbar motor column (L1-L6), and L5 dorsal root ganglion (DRG) were counted as described previously (Li et al., 1995).

Immunofluorescent staining. Cryosections ( $8 \mu \mathrm{m}$; Leica) prepared from E18.5 brain and cells cultured on chamber slides were fixed with $4 \%$ paraformaldehyde in PBS and stained with anti-glial fibrillary acidic protein (GFAP) antibody (Dako, High Wycombe, UK) and rhodamineconjugated second antibody (Chemicon, Temecula, CA). For the cultured cells, bisbenzimide H33258 fluorochrome trihydrochloride (Nakaraitesque, Kyoto, Japan) was used to stain nuclei.

Neuron survival assay. T11-L3 DRGs were dissected from each E18.5 mouse and chopped briefly with a pair of $27 \mathrm{G}$ needles in DMEM. Chopped DRGs from each individual mouse were pooled in one well of a 96-well round-bottom plate and resuspended with $150 \mu$ l of dissociation buffer (DMEM containing $0.025 \%$ trypsin, $0.01 \%$ DNase, and $10 \mathrm{~mm}$ $\mathrm{HEPES}, \mathrm{pH} 7.5$ ). Plates were incubated at $37^{\circ} \mathrm{C}$ in a humidified chamber and occasionally tapped to suspend DRG fragments in every 5 min. After 10-15 $\mathrm{min}, 50 \mu \mathrm{l}$ of FCS was added to each well to stop trypsinization. DRG cells were gently suspended with $1 \mathrm{ml}$ pipet tip (Gilson) and passed through \#300 nylon mesh to remove debris and aggregates. Cells were plated in duplicates in flat-bottom 96-well Biocoat poly-D-lysine-mouse laminin plates (Becton Dickinson, Cockeysville, MD) at a final density of 200 cells per well in $200 \mu \mathrm{l}$ of DMEM-F-12 containing $10 \% \mathrm{FCS}$. The following factors were used: $1 \mu \mathrm{g} / \mathrm{ml} \mathrm{IL-6,} 1 \mu \mathrm{g} / \mathrm{ml} \mathrm{sIL-6R,} 300 \mathrm{ng} / \mathrm{ml}$ OSM (Peprotech, Rocky Hill, NJ), 300 ng/ml LIF (Genzyme), 300 ng/ml CNTF (Genzyme), and $100 \mathrm{ng} / \mathrm{ml}$ NGF (Toyobo, Tokyo, Japan). Cells were incubated for $20 \mathrm{hr}$, and large bright cells observed under phasecontrast microscopy were counted.

\section{RESULTS}

\section{Impairment of astrocyte differentiation in the absence of gp130 signaling}

Neuroepithelial cells from E14.5 fetal telencephalon are considered to contain neuroglial stem cells and have been shown to differentiate into astrocytes when cultured with LIF and CNTF (Johe et al., 1996; Bonni et al., 1997; McKay, 1997). To examine the effect of gp130 deficiency on astrocyte differentiation, we cultured neuroepithelial cells from the gp130 knock-out mice. In these cells, gp130 signaling is completely missing. As shown in Figure $1 A$, no tyrosine phosphorylation of gp130 or STAT3 was observed in gp130 - /- neuroepithelial cells stimulated with either LIF or a combination of IL-6 and sIL-6R, unlike in the case of the wild-type control. In LIF-stimulated normal control cells, tyrosine phosphorylation of LIFR was also observed, which was completely missing in gp130 $-/-$ cells.

E14.5 neuroepithelial cells were then examined for their potential to differentiate into astrocytes in the presence of gp130stimulating cytokines. Astrocytes positive for their marker protein GFAP were definitely induced in the normal control cell cultures containing IL-6 plus sIL-6R, LIF, or CNTF (Fig. 1B, $b-d)$. In marked contrast, no GFAP-positive astrocyte was observed under the same culture conditions when cells were derived from gp130-/- telencephalon (Fig. $1 B, f-h$ ). No cells with glial morphology are found in the cultures of gp130-deficient cells (data not shown), suggesting that gp130 signaling is important for the induction of not only GFAP expression but also glial morphology.

Based on these results obtained in vitro, we wanted to know whether GFAP-positive astrocytes develop in vivo in the absence of gp130 signaling. When analyzed by Northern blotting, the amount of GFAP mRNA in E18.5 gp130 - /- brain was dramatically reduced to a nearly negligible level (Fig. $2 A$ ). GFAP mRNA expression in gp130 $+/-$ brain showed some reduction.

To further demonstrate impairment of astrocyte development in gp130-deficient mice, cryosections from the gp130 -/- E18.5 brain were stained with anti-GFAP antibody. As shown in Figure $2 B$, the intensity of GFAP immunoreactivity and the positively stained area were dramatically reduced in gp130-deficient mice in, for instance, the fimbria and the molecular layer of dentate gyrus. Nevertheless, GFAP dull-positive cells were detected, in particular, in the fimbria of the hippocampus, suggesting that gp130-independent pathways exist that may partly contribute to the development of GFAP-positive astrocytes.

\section{Neuronal defects in gp130-deficient mice}

gp130-stimulating cytokines are known to support survival of cultured neurons (Ernsberger et al., 1989; Martinou et al., 1992; Horton et al., 1998). From the viewpoint of the survival effect of gp130 signaling, we first examined responsiveness of DRG neurons prepared from gp130 $+/+,+/-$, and $-/-$ E18.5 mice to 
A

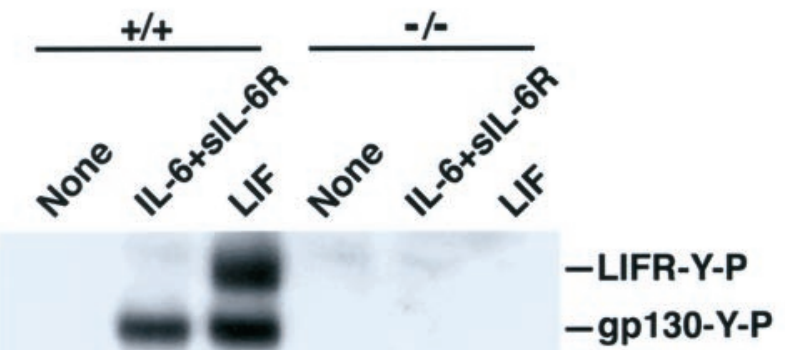

IP: $\alpha$ gp130, Blot: $\alpha$ P-Y
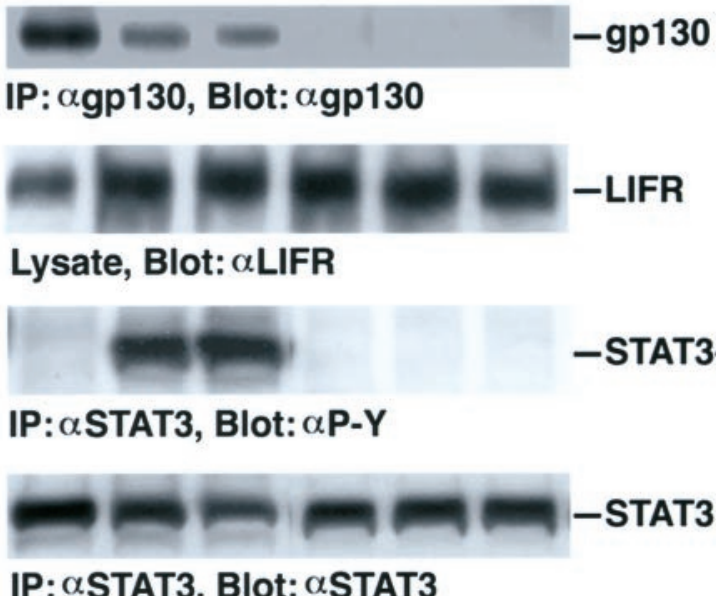

IP: $\alpha$ STAT3, Blot: $\alpha$ STAT3
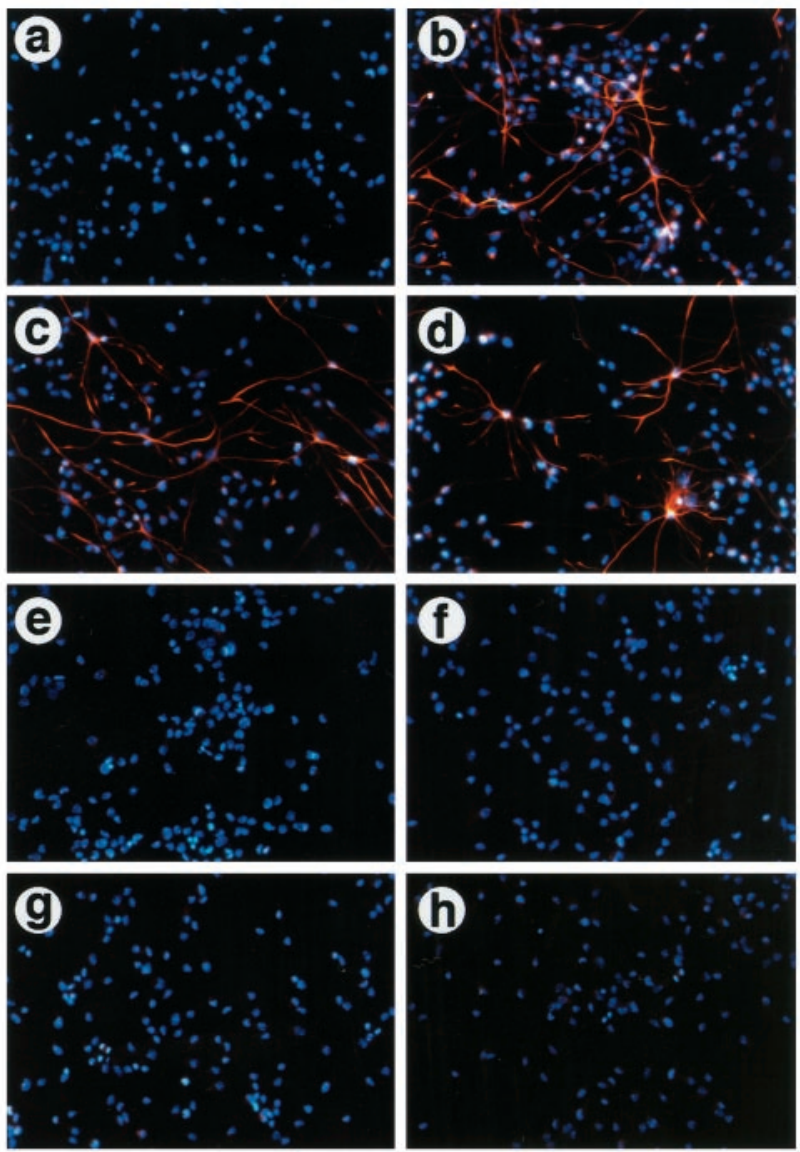

Figure 1. Impairment of astrocyte induction in neuroepithelial cells by the lack of gp130. A, Absence of gp130 signalings in gp130-deficient cells. Neuroepithelial cells from E14.5 gp130 $+/+$ and gp130 - /- mice were stimulated with either IL-6 plus sIL-6R or LIF. NP-40 lysates were subjected to immunoprecipitation and subsequent immunoblotting with the antibodies indicated, except for the middle panel in which the lysates were directly analyzed by immunoblotting. $B$, Loss of astrocyte induction in gp130-deficient cells in vitro. Neuroepithelial cells from E14.5 gp130 $+/+(a-d)$ or gp130 $-/-(e-h)$ mice were cultured as described in Materials and Methods with medium alone $(a, e)$, or IL-6 plus sIL-6R $(b, f)$, LIF $(c, g)$, or CNTF $(d, h)$ and stained for GFAP by specific antibody. GFAP-positive cells and nuclei are shown in red and blue, respectively, by fluorescent microscopy.

various cytokines in cultures. Without cytokines, most DRG neurons were dead after $20 \mathrm{hr}$ of culture, and only $10 \%$ remained alive (Fig. $3 A$ ). Neurons from gp $130+/+$ and $+/-$ DRG could be kept alive when cultured with IL-6 plus sIL-6R, OSM, LIF, CNTF, or NGF. In contrast, gp130 -/- neurons did not show any survival response to these cytokines, except for NGF, which does not use gp130 for signal transduction.

Based on the above finding, the number of neurons in the L5 DRG from E18.5 mice was counted in paraffin serial sections. As shown in Figure $3 B$ (left panel), the number of DRG neurons were significantly smaller in gp130 -/- mice than in the wildtype controls. There was, however, no significant difference in the number of E14.5 DRG neurons in gp130 +/+ and gp130 -/mice (data not shown). The second panel in Figure $3 B$ shows considerable reduction in the number of motor neurons in the facial nucleus at E18.5. An $\sim 40 \%$ reduction in the number of motor neurons in nucleus ambiguus in E18.5 gp130 - /- mice was observed (Fig. 3B, third panel). The number of spinal motor neurons in L1-L6 spinal segments of gp130 -/- mice was also significantly reduced on E18.5 (Fig. 3B, fourth panel). When counted on E14.5, the number of motor neurons in the same segments (i.e., L1-L6) of the spinal cord was not affected by the lack of gp130 $(\mathrm{gp} 130+/+, 3838 \pm 95 ; \mathrm{gp} 130-/-, 3780 \pm 540)$, as in the case of DRG sensory neurons. Figure $3 C$ shows repre- sentative histological sections of the spinal motor column in E18.5 gp130 +/+ and -/- mice. In the gp130-deficient mice, a reduction in the number of intact motor neurons and atrophy of the remaining neurons are obvious.

\section{DISCUSSION}

Considering that gp130 is required for signal transduction of all the IL-6 family of cytokines and that these cytokines signal through either gp130/gp130 homodimers, gp130/LIFR heterodimers, or gp130/OSMR heterodimers (Taga and Kishimoto, 1997), neurological phenotype of gp130-deficient mice was expected to be more severe than that of LIFR-deficient mice (Li et al., 1995; Ware et al., 1995; Koblar et al., 1998), because the latter type of mice theoretically lack the signals of LIF, CNTF, and CT-1, as well as a part of OSM signals, among the six gp130stimulating cytokines. However, by comparing the results from our present study on gp130 knock-outs and those from others on mice deficient for LIFR (Li et al., 1995) or CNTFR (DeChiara et al., 1995), it appears that motor neurons are similarly affected in these three lines of mice. Because the extent of cell death of motor neurons in gp130 null mice is not higher than that observed in LIFR null mice ( $\mathrm{Li}$ et al., 1995), it is suggested that cytokines 


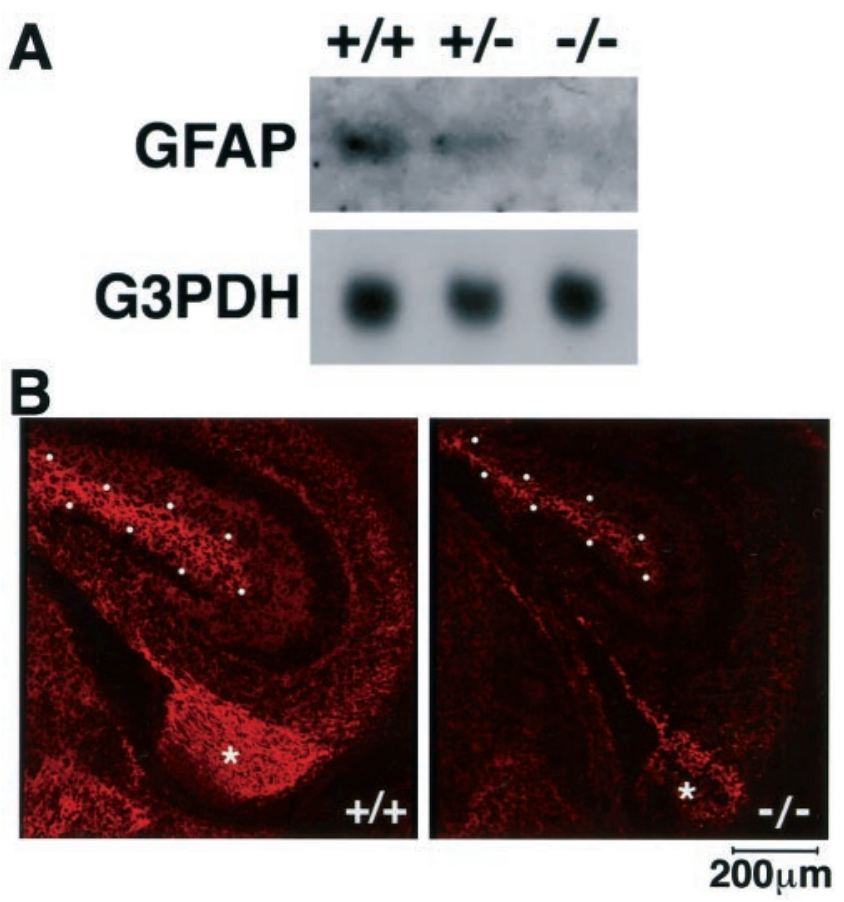

Figure 2. Impairment of GFAP expression in gp130-deficient brain. $A$, Loss of GFAP transcripts in gp130-deficient brain. RNA from E18.5 gp130 $+/+,+/-$, and $-/-$ brain was analyzed by Northern blotting with a GFAP-specific probe. $B$, Reduction of GFAP-positive cells in gp130deficient brain. Cryosections from E18.5 gp130 +/+ and gp130 - /- brain were stained with GFAP-specific antibody and rhodamine-conjugated second antibody. Asterisks indicate fimbria. The dotted outlines represent the molecular layer of dentate gyrus. No detectable staining was observed when the first antibody was omitted during the procedures (data not shown).

that signal through the gp130/LIFR heterodimer are important for the maintenance of motor neurons and that compensation through gp130/gp130 homodimers is only minor in LIFR mutant mice.

Similar discussion can be made regarding astrocyte differentiation. In the gp130-deficient brain, astrocyte differentiation was dramatically impaired. An almost comparable phenotype was observed in LIFR-deficient mice (Ware et al., 1995; Koblar et al., 1998). Among the six known IL-6 type cytokines, those signaling through gp130/LIFR heterodimers seem to be important for astrocyte differentiation as is described above for motor neuron survival. In fetal neuroepithelial cell cultures, GFAP expression is completely absent when gp130 (our present study) or downstream signaling (Bonni et al., 1997) is impaired. In the gp130 -/- mice in vivo, GFAP expression in the hippocampus is significantly reduced but not null. This suggests that other minor mechanisms may exist that can support astrocyte differentiation in vivo. A candidate for such a mechanism is bone morphogenetic protein (BMP)-induced astrocyte differentiation. When gp130 -/- neuroepithelial cells were cultured for $6 \mathrm{~d}$ with BMP2 $(80 \mathrm{ng} / \mathrm{ml})$, we observed GFAP-positive cells with astrocyte morphology, although the intensity of GFAP expression looked dull and the number of such cells was small (K. Nakashima, M. Yanagisawa, and T. Taga, unpublished data).

Mice lacking CNTFR were also reported to exhibit significant loss of motor neurons as has been observed in gp130 null mice in the present study. They, however, did not show detectable loss of DRG neurons (DeChiara et al., 1995), unlike in the case of the gp130 nulls. It will be interesting to examine whether DRG
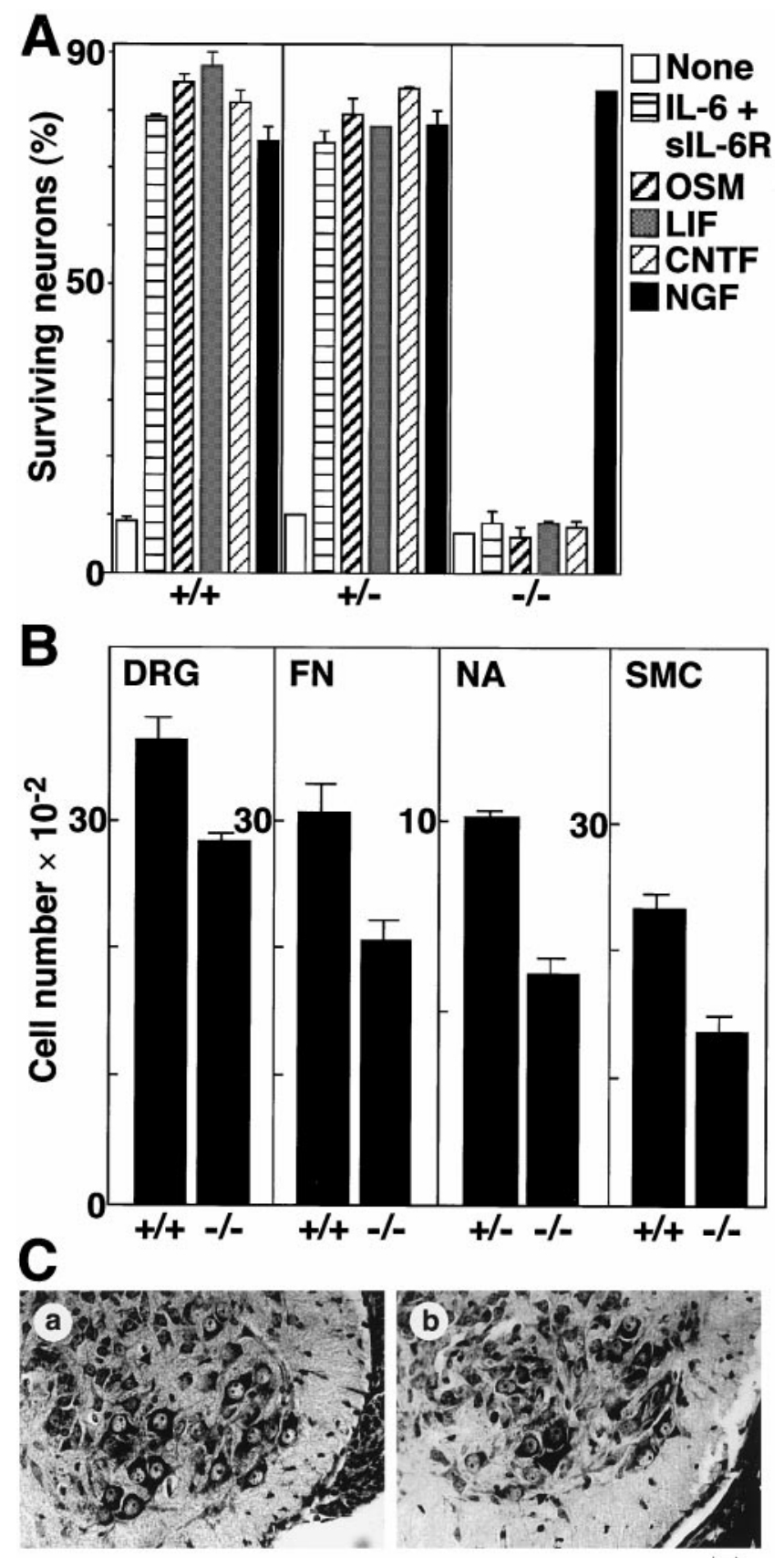

$30 \mu \mathrm{m}$

Figure 3. Neuronal defects in gp130-deficient mice. A, Complete loss of survival response of DRG neurons to gp130 stimulation. DRG neurons from E18.5 mice with the indicated genotype were cultured for $20 \mathrm{hr}$ with gp130-stimulating cytokines, as well as NGF. Live neurons were counted under phase-contrast microscopy. $B$, Reduction of neuron numbers in gp130-deficient mice. Histological sections prepared from E18.5 mice with the indicated genotype were used for counting neurons in L5 DRG $(p<0.05 ; t$ test $)$, facial nucleus $(F N)(p<0.05)$, nucleus ambiguus $(N A)$, and L1-L6 spinal motor column $(S M C)(p<0.005)$. Each column represents mean $\pm \mathrm{SD}$ of the data from three individual mice, except for gp130 +/- nucleus ambiguus in which the mean \pm SD fluctuation of the data from two mice was indicated. $C$, Histological view of spinal motor neurons. Representative sections from gp130 $+/+(a)$ and gp130 - / $(b)$ spinal ventral horn are shown. 
neurons are affected in mice deficient for LIFR. As we have shown in this study, DRG neurons are significantly reduced by $\sim 20 \%$ in gp130 null mice. The obvious responsiveness of DRG sensory neurons from gp130 -/ - mice to factors such as NGF could explain why $80 \%$ of them can be maintained in the absence of gp130. There have been several reports showing sensory neuron deficits in the DRG of mice lacking, for instance, NGF, TrkA, TrkB, GDNF, and BDNF (Snider, 1994). Signals regulated by these factors and receptors may compensate for the lack of those regulated by gp130 to support survival of DRG sensory neurons.

Among the three gp130-associating Janus kinase (JAK) family kinases (JAK1, JAK2, and TYK2) (Narazaki et al., 1994; Taga and Kishimoto, 1997), JAK1 has been suggested to play a primarily important role (Guschin et al., 1995). Consistent with this suggestion, it was reported recently that JAK1 deficiency resulted in significant loss of DRG neuron numbers and almost complete loss of responsiveness of DRG neurons to gp130-stimulating cytokines (Rodig et al., 1998). It should be noted, however, that the number of DRG neurons in JAK1-deficient mice appears more reduced than that in gp130 null mice. This suggests that JAK1 may also be involved in signal transduction of factors besides the IL-6 type cytokines.

As for motor neurons, degeneration in the absence of gp130 in vivo was dramatic (by 40\%) (Fig. 3B). The higher loss of motor neurons compared with DRG sensory neurons suggests that fewer back-up mediators for motor neurons exist in gp130 -/- mice. In this context, it should be noted that primarily affected neurons at the immediate postnatal stage in mice deficient for CNTFR or LIFR are motor neurons (DeChiara et al., 1995; Li et al., 1995) and that CNTF-deficient adult mice exhibit loss of motor neurons but not other neurons (Masu et al., 1993). The findings that motor neurons are more affected than sensory neurons in gp130 -/mice could be of relevance to the understanding of motor neuron diseases. In the case of amyotrophic lateral sclerosis, loss of sensory neurons has been observed, which is, however, much lower than the loss of motor neurons and does not lead to severe clinical symptoms (Dyck et al., 1975; Jamal et al., 1985). It will be interesting to know whether gp130-dependent signaling pathways are disturbed in such patients with motor neuron diseases.

Various neuropoietic and neurotrophic factors are known to support neuronal differentiation, innervation, and maintenance during development. Preference of such factors required by a neuronal lineage of cells may change in the course of development. The present study has shown that gp130 deficiency did not result in detectable neuronal defect on E14.5 but did lead to significant loss of both motor and sensory neurons on E18.5. This suggests that gp130-stimulating cytokines may not function in neuronal differentiation during earlier developmental stages but may have an important role in the maintenance of already differentiated neurons. A supportive evidence for this idea is that survival response of trigeminal ganglion neurons to gp130stimulating cytokines is almost negligible on day 14 of development but is dramatically increased on day 19 to the extent almost comparable with that observed with NGF (Horton et al., 1998), as has been demonstrated by our experiments in Figure $3 A$. Another supportive report is that transgenic mice with forced expression of IL-6 and IL-6R show constitutive activation of gp130 and exhibit accelerated motor nerve regeneration after surgical injury of hypoglossal nerve, although these mice have a developmentally normal number of hypoglossal motor neurons (Hirota et al., 1996). LIF and CNTF have been suggested to function as a cholinergic differentiation factor that induces a transmitter switch from noradrenergic phenotype to a cholinergic one in cultured sympathetic neurons (Yamamori et al., 1989; Patterson, 1994). However, mice lacking CNTF, LIF, or both did not show detectable developmental abnormalities in cholinergic properties of parasympathetic neurons, at least in the sweat glands and periosteum (Francis et al., 1997), whereas injury response of differentiated sympathetic neurons was affected at least in LIF-deficient mice (Rao et al., 1993).

It has been suggested that there exists a common neural precursor that can differentiate into both neurons and astrocytes (Turner and Cepko, 1987; Kilpatrick and Bartlett, 1995; Bonni et al., 1997; McKay, 1997). In gp130 knock-out mice, both of these neural cell populations at the late developmental stage were affected. However, our results suggest that the deficits observed in motor neurons and astrocytes are probably not a result of actions through gp130 at the stem cell level, because E14.5 gp130 null mice have normal numbers of motor neurons and sensory neurons.

In the present study, we have focused on the neurological defects in gp130-deficient mice at the late stage of development. gp130-deficient mice die during development and shortly after birth. Even the live-born gp130 -/- mice on the ICR genetic background die shortly after birth without feeding. It will be interesting to examine relevance between the neurological abnormalities found in E18.5 gp130 - / - mice and neonatal death of this line of mice. With the use of these mice, physiological function of gp130 after birth could not be examined. Therefore, techniques have been developed to inactivate gp130 in mice by application of the Cre/loxP-mediated recombination system. By these techniques, Betz et al. (1998) were able to show that postnatal Schwann cells depend on gp130 for their integrity and the maintenance of myelinated and unmyelinated peripheral nerve fibers. With the improvement of appropriate techniques to delete gp130 specifically in postnatal motor neurons and astrocytes, it will be possible to examine whether gp130-dependent signaling pathways are also necessary for the maintenance of adult motor neurons and astrocytes and whether the dependence on the gp130 signals increase or decrease during postnatal development.

\section{REFERENCES}

Barres BA, Burne JF, Holtmann B, Thoenen H, Sendtner M, Raff MC (1996) Ciliary neurotrophic factor enhances the rate of oligodendrocyte generation. Mol Cell Neurosci 8:146-156.

Betz UAK, Bloch W, van den Broeck M, Yoshida K, Taga T, Zinkernagel R, Kishimoto T, Addicks K, Rajewsky K, Müller WJ (1998) Postnatally induced inactivation of gp130 in mice results in neurological, cardiac, hematopoietic, immunological, hepatic and pulmonary defects. J Exp Med 188:1955-1965.

Bonni A, Sun Y, Nadal-Vicens M, Bhatt A, Frank DA, Rozovsky I, Stahl N, Yancopoulos GD, Greenberg ME (1997) Regulation of gliogenesis in the central nervous system by the JAK-STAT signaling pathway. Science 278:477-483.

Davis S, Aldrich TH, Stahl N, Pan L, Taga T, Kishimoto T, Ip NY, Yancopoulos GD (1993) LIFR $\beta$ and gp130 as heterodimerizing signal transducers of the tripartite CNTF receptor. Science 260:1805-1808.

DeChiara TM, Vejsada R, Poueymirou WT, Acheson A, McClain J, Pan L, Stahl N, Ip NY, Kato A, Yancopoulos GD (1995) Mice lacking the CNTF receptor, unlike mice lacking CNTF, exhibit profound motor neuron deficits at birth. Cell 83:313-322.

Dyck PJ, Stevens JC, Mulder DW, Espinosa RE (1975) Frequency of nerve fiber degeneration of peripheral motor and sensory neurons in amyotrophic lateral sclerosis: morphometry of deep and superficial peroneal nerves. Neurology 25:781-787.

Ernsberger U, Sendtner M, Rohrer H (1989) Proliferation and differentiation of embryonic chick sympathetic neurons: effects of ciliary neurotrophic factor. Neuron 2:1275-1284. 
Escary JL, Perreau J, Duménil D, Ezine S, Brulet P (1993) Leukemia inhibitory factor is necessary for maintenance of haematopoietic stem cells and thymocyte stimulation. Nature 363:361-364.

Francis NJ, Asmus SE, Landis SC (1997) CNTF and LIF are not required for the target-directed acquisition of cholinergic and peptidergic properties by sympathetic neurons in vivo. Dev Biol 182:76-87.

Guschin D, Rogers N, Briscoe J, Witthuhn B, Watling D, Hom F, Pellegrini S, Yasukawa K, Heinrich P, Stark GR, Ihle JN, Kerr IM (1995) A major role for the protein tyrosine kinase JAK1 in the JAK/STAT signal transduction pathway in response to interleukin-6. EMBO J 14:1421-1429.

Hirota H, Kiyama H, Kishimoto T, Taga T (1996) Accelerated nerve regeneration in mice by upregulated expression of interleukin (IL) 6 and IL-6 receptor after trauma. J Exp Med 183:2627-2634.

Horton AR, Bartlett PF, Pennica D, Davies M (1998) Cytokines promote the survival of mouse cranial sensory neurons at different developmental stages. Eur J Neurosci 10:673-679.

Jamal GA, Wei AI, Hansen S, Ballantyne JP (1985) Sensory involvement in motor neuron disease: further evidence from automated thermal threshold determination. J Neurol Neurosurg Psychiatry 48:906-910.

Johe KK, Hazel TG, Muller T, Dugich-Djordjevic MM, McKay RDG (1996) Single factors direct the differentiation of stem cells from the fetal and adult central nervous system. Genes Dev 10:3129-3140.

Kawasaki K, Gao YH, Yokose S, Kaji Y, Nakamura T, Suda T, Yoshida K, Taga T, Kishimoto T, Kataoka H, Yuasa T, Norimatsu H, Yamaguchi A (1997) Osteoclasts are present in gp130-deficient mice. Endocrinology 138:4959-4965.

Kilpatrick TJ, Bartlett PF (1995) Cloned multipotential precursors from the mouse cerebrum require FGF-2, whereas glial restricted precursors are stimulated with either FGF-2 or EGF. J Neurosci 15:3653-3661.

Kishimoto T, Taga T, Akira S (1994) Cytokine signal transduction. Cell 76:253-262.

Koblar SA, Turnley AM, Classon BJ, Reid KL, Ware CB, Cheema SS, Murphy M, Bartlett PF (1998) Neural precursor differentiation into astrocytes requires signaling through the leukemia inhibitory factor receptor. Proc Natl Acad Sci USA 95:3178-3181.

Kopf M, Baumann H, Freer G, Freudenberg M, Lamers M, Kishimoto T, Zinkernagel R, Bluethmann H, Kàhler G (1994) Impaired immune and acute-phase responses in interleukin-6-deficient mice. Nature 368:339-342.

Li M, Sendtner M, Smith A (1995) Essential function of LIF receptor in moter neurons. Nature 378:724-727.

Martinou JC, Martinou I, Kato AC (1992) Cholinergic differentiation factor $(\mathrm{CDF} / \mathrm{LIF})$ promotes survival of isolated rat embryonic motoneurons in vitro. Neuron 8:737-744.

Masu Y, Wolf E, Holtmann B, Sendtner M, Brem G, Thoenen H (1993) Disruption of the CNTF gene results in motor neuron degeneration. Nature 365:27-32.

McKay R (1997) Stem cells in the central nervous system. Science 276:66-71.

Mehler MF, Rozental R, Dougherty M, Spray DC, Kessler JA (1993) Cytokine regulation of neuronal differentiation of hippocampal progenitor cells. Nature 362:62-65.

Murakami M, Hibi M, Nakagawa N, Nakagawa T, Yasukawa K, Yamanishi K, Taga T, Kishimoto T (1993) IL-6-induced homodimerization of gp130 and associated activation of a tyrosine kinase. Science 260:1808-1810.

Narazaki M, Witthuhn BA, Yoshida K, Silvennoinen O, Yasukawa K, Ihle JN, Kishimoto T, Taga T (1994) Activation of JAK2 kinase mediated by the interleukin 6 signal transducer gp130. Proc Natl Acad Sci USA 91:2285-2289.

Patterson PH (1994) Leukemia inhibitory factor, a cytokine at the inter- face between neurobiology and immunology. Proc Natl Acad Sci USA 91:7833-7835.

Rao MS, Sun Y, Escary JL, Perreau J, Tresser S, Patterson PH, Zigmond RE, Brulet P, Landis SC (1993) Leukemia inhibitory factor mediates an injury response but not a target-directed developmental transmitter switch in sympathetic neurons. Neuron 11:1175-1185.

Rodig SJ, Meraz MA, White JM, Lampe PA, Riley JK, Arther CD, King KL, Sheehan KCF, Yin L, Pennica D, Johnson Jr EM, Schreiber RD (1998) Disruption of the JAK1 gene demonstrates obligatory and nonredundant roles of the Jaks in cytokine-induced biologic responses. Cell 93:373-383.

Satoh T, Nakamura S, Taga T, Matsuda T, Hirano T, Kishimoto T, Kaziro Y (1988) Induction of neuronal differentiation in PC12 cells by B cell stimulatory factor 2/Interleukin 6. Mol Cell Biol 8:3546-3549.

Sendtner M, Gotz R, Holtmann B, Escary JL, Masu Y, Carroll P, Wolf E, Brem G, Brulet P, Thoenen H (1996) Cryptic physiological trophic support of motoneurons by LIF revealed by double gene targeting of CNTF and LIF. Curr Biol 6:686-694.

Snider WD (1994) Functions of the neurotrophins during nervous development: what the knockouts are teaching us. Cell 77:627-638.

Stahl N, Yancopoulos GD (1994) The tripartite CNTF receptor complex: activation and signaling involves components shared with other cytokines. J Neurobiol 25:1454-1466.

Stewart CL, Kaspar P, Brunet LJ, Bhatt H, Gadi I, Kàntgen F, Abbondanzo JS (1992) Blastocyst implantation depends on maternal expression of leukaemia inhibitory factor. Nature 359:76-79.

Taga T (1996) gp130, a shared signal transducing receptor component for hematopoietic and neuropoietic cytokines. J Neurochem 67:1-10.

Taga T, Kishimoto T (1997) gp130 and the interleukin-6 family of cytokines. Annu Rev Immuol 15:797-819.

Taga T, Hibi M, Hirata Y, Yamasaki K, Yasukawa K, Matsuda T, Hirano T, Kishimoto T (1989) Interleukin-6 triggers the association of its receptor with a possible signal transducer, gp130. Cell 58:573-581.

Taga T, Narazaki M, Yasukawa K, Saito T, Miki D, Hamaguchi M, Davis S, Shoyab M, Yancopoulos GD, Kishimoto T (1992) Functional inhibition of hematopoietic and neurotrophic cytokines by blocking the interleukin 6 signal transducer gp130. Proc Natl Acad Sci USA 89:10998-11001.

Turner DL, Cepko CL (1987) A common progenitor for neurons and glia persists in rat retina late in development. Nature 328:131-136.

Ware CB, Horowitz MC, Renshaw BR, Hunt JS, Liggitt D, Koblar SA, Gliniak BC, McKenna HJ, Papayannopoulou T, Thoma B, Cheng L, Donovan PJ, Peschon JJ, Bartlett PF, Willis CR, Wright BD, Carpenter MK, Davison BL, Gearing DP (1995) Targeted disruption of the low-affinity leukemia inhibitory factor receptor gene causes placental, skeletal, neural and metabolic defects and results in perinatal death. Development 121:1283-1299.

Yamamori T, Fukada K, Aebersold R, Korsching S, Fann MJ, Patterson PH (1989) The cholinergic neuronal differentiation factor from heart cells is identical to leukemia inhibitory factor. Science 246:1412-1416.

Yoshida K, Taga T, Saito M, Suematsu S, Kumanogoh A, Tanaka T, Fujiwara H, Hirata M, Yamagami T, Nakahata T, Hirabayashi T, Yoneda Y, Tanaka K, Wang WZ, Mori C, Shiota K, Yoshida N, Kishimoto T (1996) Targeted disruption of gp130, a common signal transducer for IL-6-family of cytokines, leads to myocardial and hematological disorders. Proc Natl Acad Sci USA 93:407-411.

Yoshida K, Taga T, Saito M, Kumanogoh A, Tanaka T, Ozono K, Nakayama M, Nakahata T, Yoshida N, Kishimoto T (1998) Myocardial, hematological, and placental disorders caused by targeted disruption of gp130, a common signal transducer for IL-6 family of cytokines. In: Contemporary immunology: cytokine knockouts (Durum SK, Muegge K, eds), pp 259-286. Totowa, NJ: Humana. 